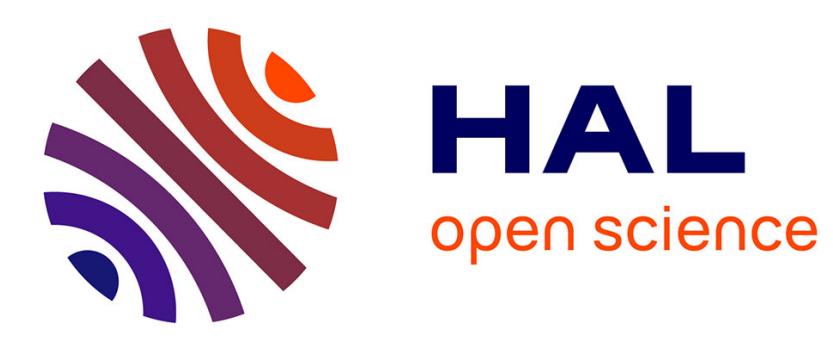

\title{
The effects of PLA color on material properties of 3-D printed components
}

Joshua Pearce, Ben T Wittbrodt

\section{To cite this version:}

Joshua Pearce, Ben T Wittbrodt. The effects of PLA color on material properties of 3-D printed components. Additive Manufacturing, 2015, 8, pp.110-116. 10.1016/j.addma.2015.09.006 . hal02113573

\section{HAL Id: hal-02113573 \\ https://hal.science/hal-02113573}

Submitted on 29 Apr 2019

HAL is a multi-disciplinary open access archive for the deposit and dissemination of scientific research documents, whether they are published or not. The documents may come from teaching and research institutions in France or abroad, or from public or private research centers.
L'archive ouverte pluridisciplinaire HAL, est destinée au dépôt et à la diffusion de documents scientifiques de niveau recherche, publiés ou non, émanant des établissements d'enseignement et de recherche français ou étrangers, des laboratoires publics ou privés. 
Preprint: Wittbrodt, B., \& Pearce, J. M. (2015). The Effects of PLA Color on Material Properties of 3-D Printed Components. Additive Manufacturing. 8, 110-116 (2015). DOI: http://dx.doi.org/10.1016/j.addma.2015.09.006

\author{
The Effects of PLA Color on Material Properties of 3-D Printed Components \\ Ben Wittbrodt ${ }^{1}$ and Joshua M. Pearce ${ }^{1,2, *}$ \\ ${ }^{1}$ Department of Materials Science \& Engineering, Michigan Technological University, \\ Houghton, MI 49931, USA \\ 2 Department of Electrical \& Computer Engineering, Michigan Technological \\ University, Houghton, MI 49931, USA
}

*Corresponding author: Michigan Technological University, 601 M\&M Building, 1400 Townsend Drive, Houghton, MI 49931-1295 (pearce@mtu.edu) ph: 906-487-1466

\begin{abstract}
As the number of prosumer printers has expanded rapidly, they now make up the majority of the 3-D printer market and of these printers those in the open-source lineage of the RepRap also have expanded to dominate. Although still primarily used for prototyping or hobbyist production of low-value products, the RepRap has the capacity to be used for high-value distributed manufacturing. A recent study found that RepRap printed parts printed in realistic environmental conditions can match and even out perform commercial 3-D printers using proprietary FDM in terms of tensile strength with the same polymers. However, tensile strengths of the large sample set of RepRap prints fluctuated. In order to explain that fluctuation and better inform designers on RepRap print properties this study determines the effect of color and processing temperature on material properties of Lulzbot TAZ deposited PLA in various colors. Five colors (white, black, blue, grey, and natural) of commercially available filament processed from 4043D PLA is tested for for crystallinity with XRD, tensile strength following ASTM D638 and the microstructure is evaluated with environmental scanning electron microscope. Results are presented showing a strong relationship between tensile strength and percent crystallinity of a 3-D printed sample and a strong relationship between percent crystallinity and the extruder temperature. Conclusions are drawn about the effects of color and processing temperature on the material properties of 3-D printed PLA to promote the open-source development of RepRap 3-D printing.
\end{abstract}

Keywords: Mechanical Properties; Distributed Manufacturing; RepRap; Plastic Color; Crystallinity

\title{
1. Introduction:
}

With the rise in popularity of low-cost at-home 3-D printers using fused filament fabrication (FFF) (material extrusion by ASTM Standard F2792-12a), specifically the open-source RepRap (self-Replicating Rapid prototyper) [1-4], comes a demand for the education about how to properly use and apply the technology. It is estimated that the consumer, low cost, 3-D printing market will reach $\$ 5.1$ billion in revenue by $2018[4,5]$. Additive manufacturing took 20 years to reach a $\$ 1$ billion USD and has grown to $\$ 3.07$ billion USD two years later in 2013 [4]. There have been efforts made already to promote the use of at-home 3-D printing [6] and it has been shown that decentralizing the manufacturing process not only allows for a lower cost of goods for the consumer[7], but a lower impact on the environment as well [8]. There has been an exponential growth of open-source designs for 3-D printing and this trend is expected to continue growing as consumer level 3-D has been proven to be an economically viable purchase for American middle-class consumers [7]. Prosumer 3-D printers in general, and more specifically, RepRap 3$\mathrm{D}$ printers account for the majority of 3-D printers in use now [9]. In addition, the appeal of democratized manufacturing has been moving from an exclusively hobbyist idea to become more commonplace [10]. Currently, there are many different materials available on the market for prosumer FFF 3-D printing 
Preprint: Wittbrodt, B., \& Pearce, J. M. (2015). The Effects of PLA Color on Material Properties of 3-D Printed Components. Additive Manufacturing. 8, 110-116 (2015). DOI: http://dx.doi.org/10.1016/j.addma.2015.09.006

including ABS, Nylon, polycarbonate, high-density polyethylene, high impact polystyrene, PLA (polylactic acid), and others [11]. PLA has emerged as one of the favorites among the prosumer 3-D printer users. PLA has a relatively low melting point, $150^{\circ}-160^{\circ} \mathrm{C}$, thus requiring less energy to print with the material, which also provides advantages for off-grid applications in the developing world [12]. In addition, PLA has been shown to be a safer alternative to the possibly toxic ABS plastic [13]. With the introduction of many new and affordable 3-D printing technologies the amount of materials that may become common will grow $[14,15]$. Efforts have been made to add strengthening agents to common 3-D printable materials [16,17], and treating 3-D printable materials to increase strength [18]. With the introduction of Recyclebot, an open-source prosumer plastic filament extruder, these potential strengthening mechanisms can be implemented and tested by the end-user directly [19].

However, there is a severe lack of data and standards relating to the prosumer low-cost entry-level 3-D printing material properties, and few studies centered around commercial printers, that limits the applications with the result that prosumers are focusing on lower value products (e.g. toys) at the expense of more sophisticated designs for higher value products like tools or scientific equipment [20-22]. Current studies have described what effect the orientation of layers may have on the properties by using commercial grade powder printers [23] and using commercial grade fused deposition modeling (FDM) printers has shown a strength dependency on different types of infill patterns and internal structures [24]. Using a similar 3-D printer as Rosas [24] there has been data showing the ability of printed parts to perform between $65 \%$ and $72 \%$ as well in comparison to injection molded parts of the same material [25]. Additionally, commercial printers have been used to show a difference in layer adhesion when parts were printed using various fabrication preferences, including temperature [26]. In order for users to manufacture more functional products with their RepRaps, a recent study was completed on the mechanical properties of RepRap printed parts printed in realistic environmental conditions, which showed RepRap prints can perform match and even out perform commercial 3-D printers using proprietary FDM in terms of tensile strength with the same polymers [27]. While RepRap printers can outperform commercial printers there can be inconsistencies causing the tensile strengths to fluctuate and a preliminary evaluation of the results indicated that some of the strength variation may have been due to the color of the filament [27]. In addition, as the nature of that study had different 3-D printers running at the users chosen optimal conditions the processing temperatures varies. It has been shown already that polymers will contain different degrees of crystallinity depending on the processing history and temperature [28]. Traditional manufacturing methods have also shown a relation to mechanical properties depending on the processing history [29] but this has not been proven in FFF 3-D printing industry.

In order to close the knowledge gap surrounding prosumer 3-D printed part strength and determine the effect of color and processing temperature on material properties of PLA deposited in FFF, this study characterizes 3-D printed PLA in various colors from a single supplier. Commercially available filament processed from 4043D PLA is tested from Aleph Objects for five colors: white, black, blue, grey, and natural after printing with a Lulzbot TAZ. The samples are tested for crystallinity with XRD, tensile strength following ASTM D638 and the microstructure is evaluated with environmental scanning electron microscope (ESEM). The results are presented and conclusions are drawn about the effects of color and processing temperature on the material properties of 3-D printed PLA to promote the open-source development of RepRap 3-D printing.

\section{Methods and Materials:}

All materials were shipped together and contained in a sealed box with desiccant packets to reduce moisture absorption. Additionally each spool was vacuum sealed with a desiccant packet and only opened once all parts would be printed in the same day for testing. 
Preprint: Wittbrodt, B., \& Pearce, J. M. (2015). The Effects of PLA Color on Material Properties of 3-D Printed Components. Additive Manufacturing. 8, 110-116 (2015). DOI: http://dx.doi.org/10.1016/j.addma.2015.09.006

The test samples were printed on a Lulzbot TAZ 4 open-source 3-D printer supplied by Aleph Objects Inc. (Aleph Objects 2014) using 3mm PLA filament from Lulzbot in the following colors: natural, white, black, silver, and blue. All parts, tensile and X-ray diffraction were printed with identical parameters at $190^{\circ} \mathrm{C}$ for the extruder and $60^{\circ} \mathrm{C}$ for the build platform. Samples were printed with $100 \%$ infill and an alternating fill pattern of parallel to axis of pull and perpendicular as used for each layer. Additionally, white samples were printed with varying extruder temperatures between $190^{\circ} \mathrm{C}$ and $215^{\circ} \mathrm{C}$.

Printed tensile samples were then subjected to tensile testing consistent with ASTM D638 standards [30] with an STL found here [31] using an Instron 4206 tensometer. In addition XRD samples [32] were printed at 100\% infill and measured using a Scintag XDS-2000 Powder diffractometer, with specific goals of measuring percent crystalinity, at the Michigan Tech Applied Chemical and Morphological Analysis Laboratory (ACMAL) [33]. Cu k $\alpha$ radiation was used with scan settings 5-50 ${ }^{\circ}(2 \theta)$ with count times of 2.5 seconds per $0.2^{\circ}(2 \theta)$ following procedures outlined by MOST [34]. Once the XRD samples were run an analysis of the percent crystallinity of each sample was performed using Pearson 7 peak fitting within the DSMNT software to fit the amorphous peaks and crystalline peaks and taking a ratio of the fitted integrated area under the diffraction peak. The tensile testing and XRD measurements utilized ten samples each of the different colors printed at $190^{\circ} \mathrm{C}$ and five samples each of the elevated temperature samples. The fracture surfaces of the samples were analyzed using a Philips XL 40 ESEM [35].

\section{Results:}

The results clearly show that percent crystallinity of 3-D printed parts is color dependent as summarized in Table 1. Natural PLA (no dye added) contains the lowest percent of crystalline regions with $0.93 \%$. In contrast the white material was shown to include the greatest percentage of crystalline regions with 5.05\%. Table 1 shows the ultimate tensile strength, the strain at that tensile strength, and the percent crystallinity averages for each color along with the associated errors.

Table 1: Ultimate tensile strength, maximum strain, and percent crystallinity as a function of color for PLA.

\begin{tabular}{lrrrr}
\hline Color & $\begin{array}{r}\text { Utlimate Tensile } \\
\text { Strength }(\mathrm{MPa})\end{array}$ & $\begin{array}{r}\text { Yield Strength } \\
(\mathrm{MPa})\end{array}$ & $\begin{array}{r}\text { Maximum Strain } \\
(\%)\end{array}$ & $\begin{array}{r}\text { Crystallinity } \\
(\%)\end{array}$ \\
\hline Natural & $57.16+/-0.35$ & $52.47+/-0.35$ & $2.35+/-0.05$ & $0.93+/-0.06$ \\
Black & $52.81+/-1.18$ & $49.23+/-1.18$ & $2.02+/-0.08$ & $2.62+/-0.09$ \\
Grey & $50.84+/-0.23$ & $46.08+/-0.23$ & $1.98+/-0.04$ & $4.79+/-0.10$ \\
Blue & $54.11+/-0.30$ & $50.10+/-0.30$ & $2.13+/-0.02$ & $4.85+/-0.15$ \\
White & $53.97+/-0.26$ & $50.51+/-0.26$ & $2.22+/-0.04$ & $5.05+/-0.18$ \\
\hline
\end{tabular}

Figure 1 shows a selection of the raw stress-strain curve for $215^{\circ} \mathrm{C}$ white PLA and $190^{\circ} \mathrm{C}$ white PLA showing a linear section of loading before a curved area and finally a yield point and break. 
Preprint: Wittbrodt, B., \& Pearce, J. M. (2015). The Effects of PLA Color on Material Properties of 3-D Printed Components. Additive Manufacturing. 8, 110-116 (2015). DOI: http://dx.doi.org/10.1016/j.addma.2015.09.006

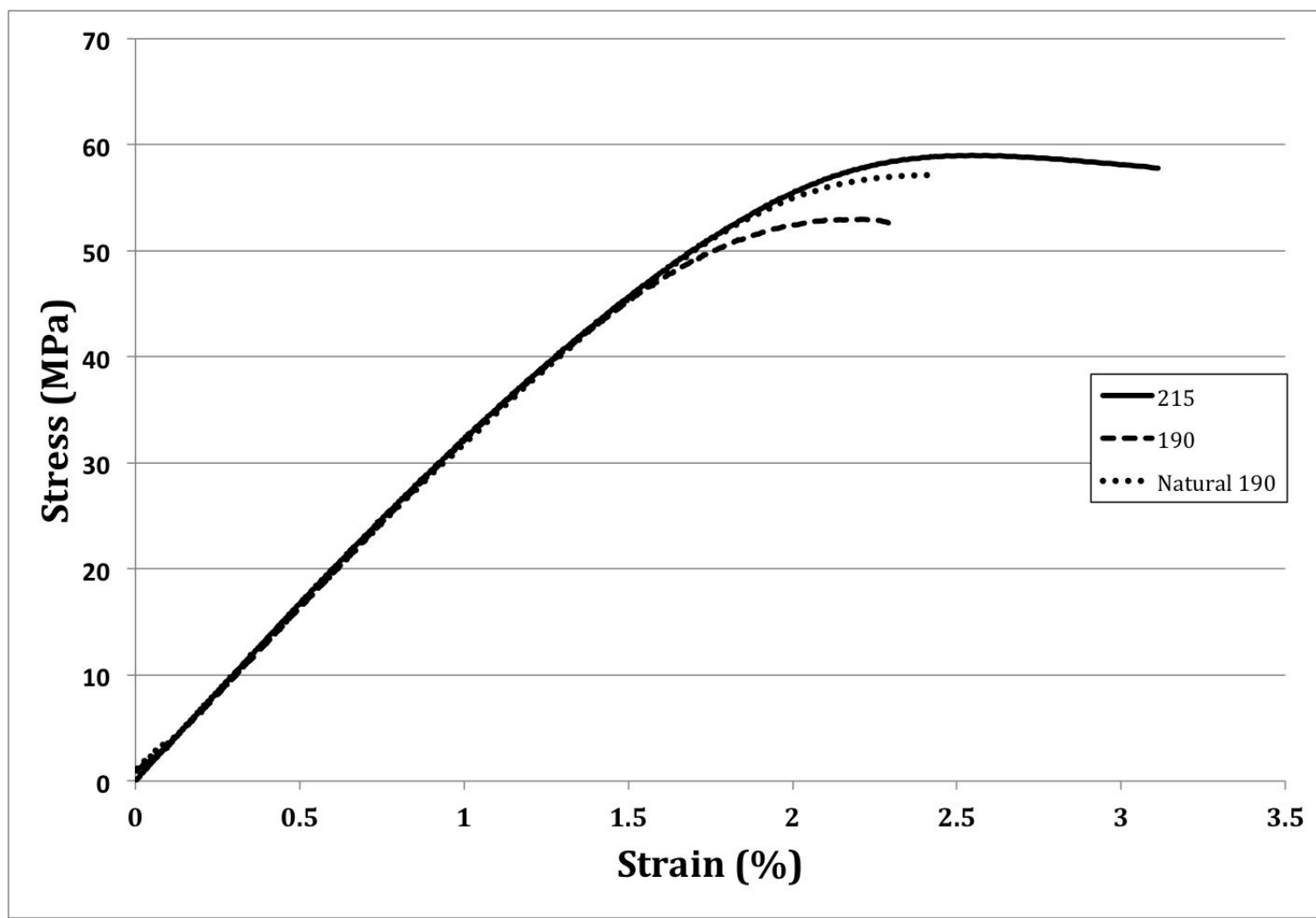

Figure 1: Raw stress vs. strain curve for white PLA printed at $215^{\circ} \mathrm{C}$ and $190^{\circ} \mathrm{C}$ and natural PLA at $190{ }^{\circ} \mathrm{C}$

The raw XRD data is plotted in Figure 2 for the different colors of PLA showing the difference in crystalline peaks as the color changes. Figure 3 shows the difference in percent crystallinity when printed at different temperatures. 
Preprint: Wittbrodt, B., \& Pearce, J. M. (2015). The Effects of PLA Color on Material Properties of 3-D Printed Components. Additive Manufacturing. 8, 110-116 (2015). DOI: http://dx.doi.org/10.1016/j.addma.2015.09.006

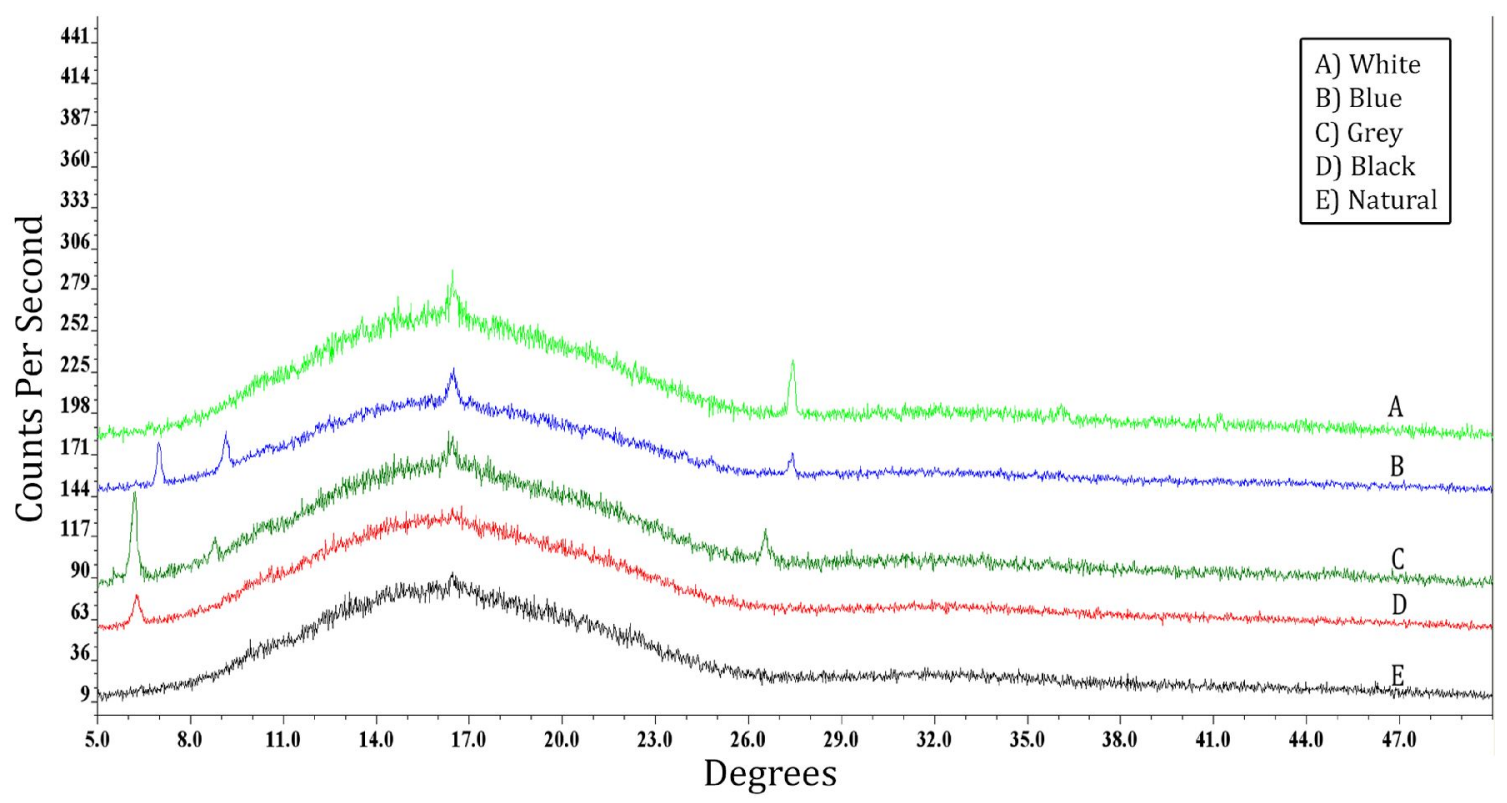

Figure 2: $\quad$ Composite XRD scans for different colors of PLA in order of percent crystallinity with the highest percent at the top. Colors: A) White, B) Blue, C) Grey, D) Black, E) Natural.

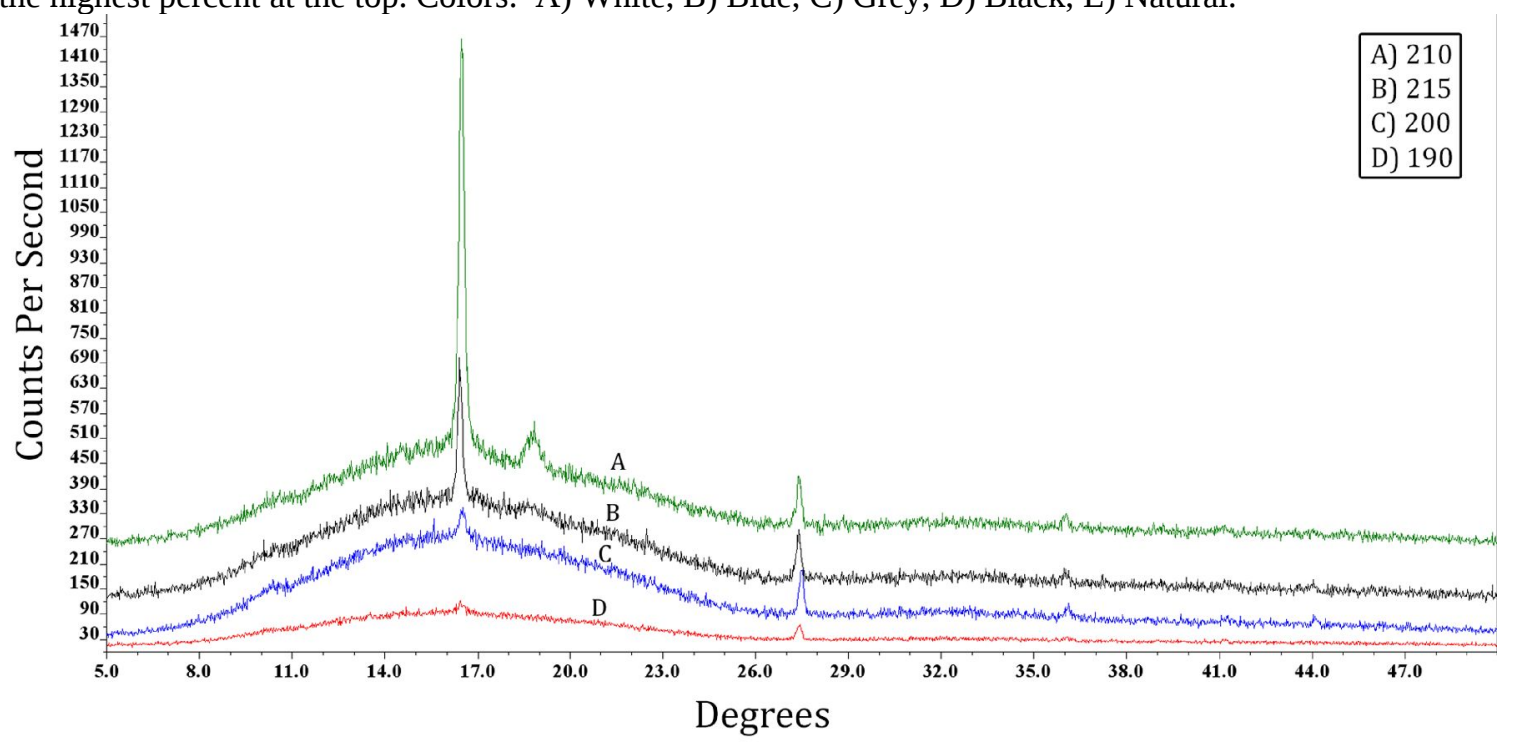

Figure 3: $\quad$ Composite XRD data (with angle in degrees 2 $\theta$ ) for white PLA when printed at various temperatures plotted with the highest percent crystallinity on top and decreasing downward. Temperatures:A) $210^{\circ} \mathrm{C}$, B) $\left.215^{\circ} \mathrm{C}, \mathrm{C}\right) 200^{\circ} \mathrm{C}$, D) $190^{\circ} \mathrm{C}$.

While Figure 3 shows that each color has a different, specific, percent crystallinity there is also a significant change in tensile strength with different percent crystallinities. The difference in tensile strengths compared to colors can be seen in Figure 4 with every sample printed at $190^{\circ} \mathrm{C}$ represented. 
Preprint: Wittbrodt, B., \& Pearce, J. M. (2015). The Effects of PLA Color on Material Properties of 3-D Printed Components. Additive Manufacturing. 8, 110-116 (2015). DOI: http://dx.doi.org/10.1016/j.addma.2015.09.006

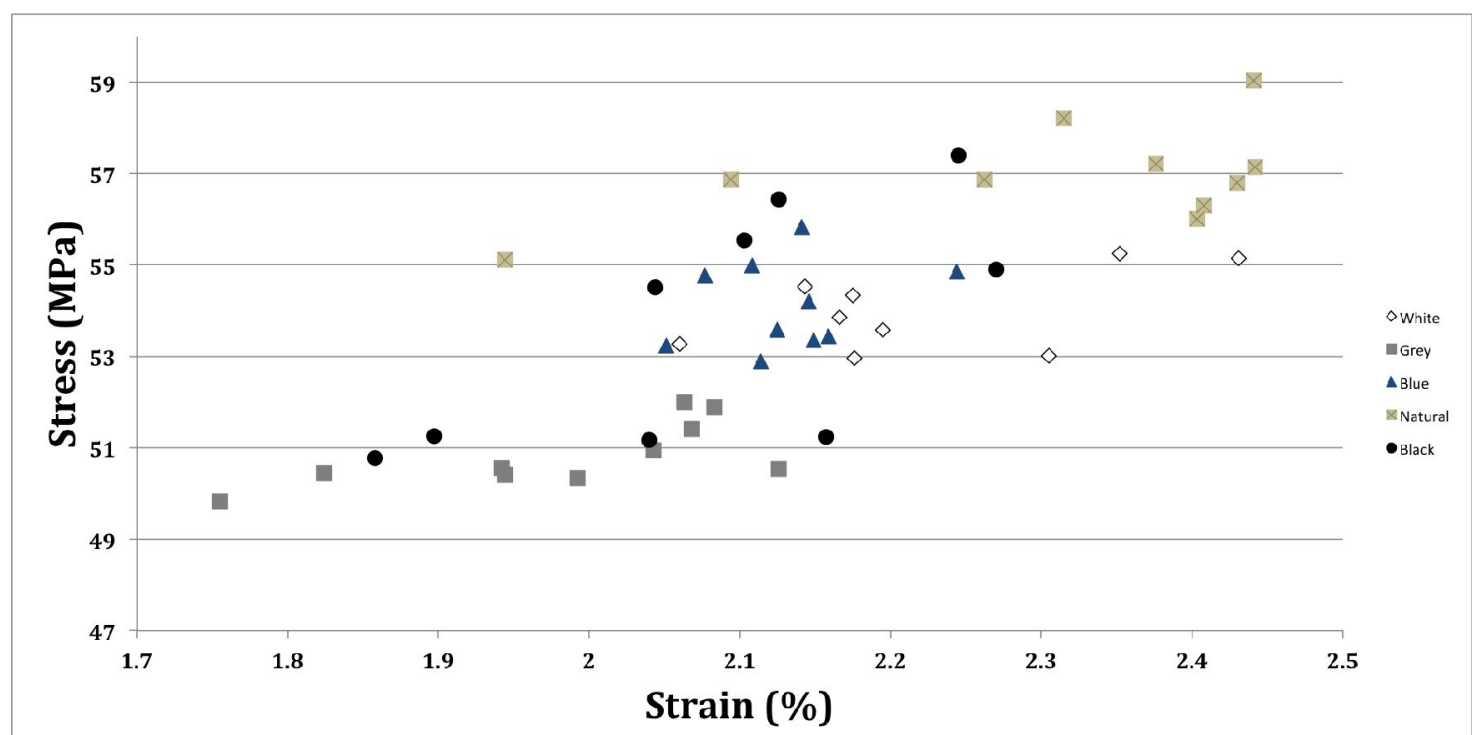

Figure 4: Maximum stress vs. Strain or printed samples

After linear fitting of the data in Figure 4 a correlation of 0.66 was obtained suggesting that there is a correlation between the tensile strength and strain of a PLA. The regression line has a slope of 11.4 suggesting a fairly significant change in ultimate tensile strength vs. strain for different colors. Standard deviations for the samples are 0.82 for white, 0.71 for grey, 0.96 for blue, 3.72 for black, and 1.09 for natural with standard errors of 0.26 for white, 0.23 for grey, 0.30 for blue, 1.8 for black, and 0.34 for natural. With the exception of black, all of these deviations are acceptable given the standard error in measurements of ultimate tensile strength as shown in Table 1.

Due to the apparent prevalence of white PLA to form crystalline regions the color was selected for additional tests. It was found that the different printing temperatures of the white PLA yielded different ultimate tensile strength and percent crystallinity results as well. Figure 5 shows the relationship between printing temperature and strength. 
Preprint: Wittbrodt, B., \& Pearce, J. M. (2015). The Effects of PLA Color on Material Properties of 3-D Printed Components. Additive Manufacturing. 8, 110-116 (2015). DOI: http://dx.doi.org/10.1016/j.addma.2015.09.006

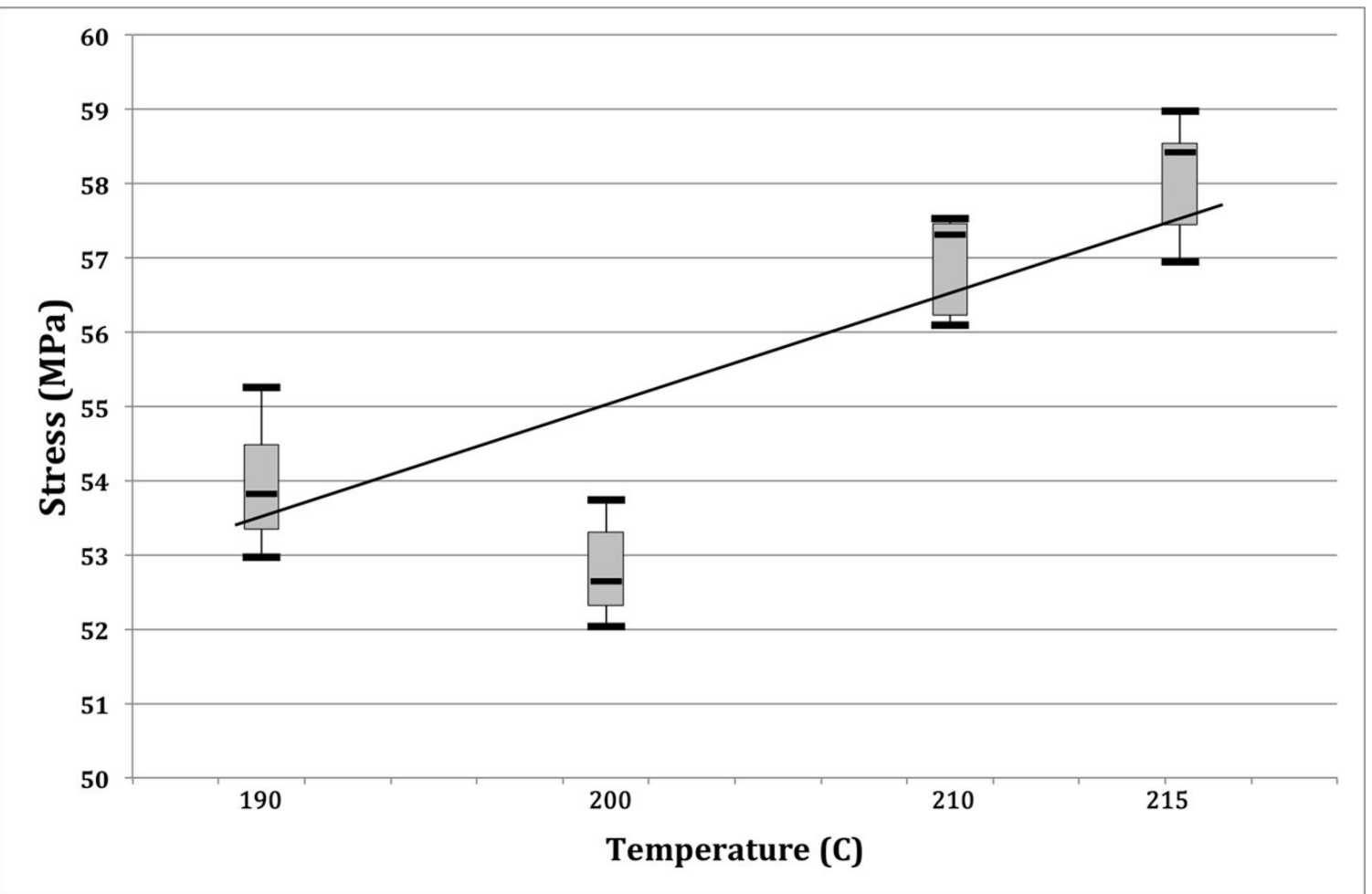

Figure 5: $\quad$ Yield strength of white PLA printed at different temperatures

Figure 5 is suggesting a mild linear relationship between strength and print temperature with a correlation value of 0.62 with all temperatures represented. In Figure 6.5 the error bars represent the minimum value, 1st quartile, median, 3rd quartile, and maximum from the bottom to top, respectively. However, if the $200^{\circ} \mathrm{C}$ samples are omitted the correlation becomes 0.85 suggesting a strong linear relationship. This temperature dependence is consistent with trends regarding there being an ideal processing temperature of a material and a range of acceptable temperatures giving similar strengths. Presented in Figure 6 are the percent crystallinities of white PLA samples printed at different temperatures. 
Preprint: Wittbrodt, B., \& Pearce, J. M. (2015). The Effects of PLA Color on Material Properties of 3-D Printed Components. Additive Manufacturing. 8, 110-116 (2015). DOI: http://dx.doi.org/10.1016/j.addma.2015.09.006

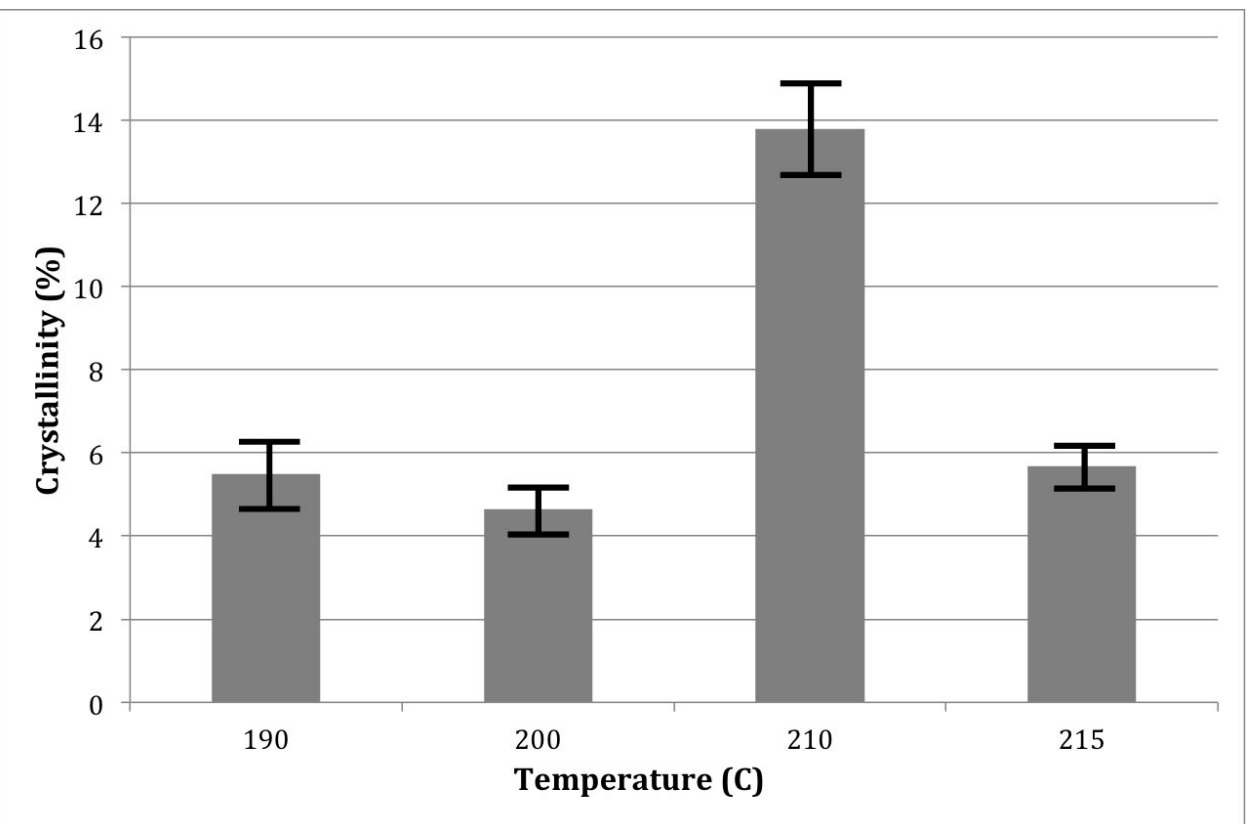

Figure 6: $\quad$ Percent crystallinity vs. temperature of printing for white PLA samples

The results shown in Figure 6 indicate that there is a critical temperature at which a maximum percent crystallinity can be achieved for white PLA. Error bars in Figure 6.6 represent +/- twice the standard error of the percent crystallinity measurement for 10 samples of each temperature.

The fracture surface of a representative sample with the ESEM is shown in Figure 7. As can be seen the difference between the nominal 100\% setting used to print the part and the actual part itself, which exhibits small (10-200 micron) extruded triangle-shaped gaps and using imageJ to analyze the area were $10.8 \%$ of the cross-section. As the extruder head temperature is increased these gaps are reduced and at some layers disappear. This can be clearly seen by comparing Figure 7 to Figure 8, which shows a higher temperature white sample and gaps accounting for $3.0 \%$. 
Preprint: Wittbrodt, B., \& Pearce, J. M. (2015). The Effects of PLA Color on Material Properties of 3-D Printed Components. Additive Manufacturing. 8, 110-116 (2015). DOI: http://dx.doi.org/10.1016/j.addma.2015.09.006

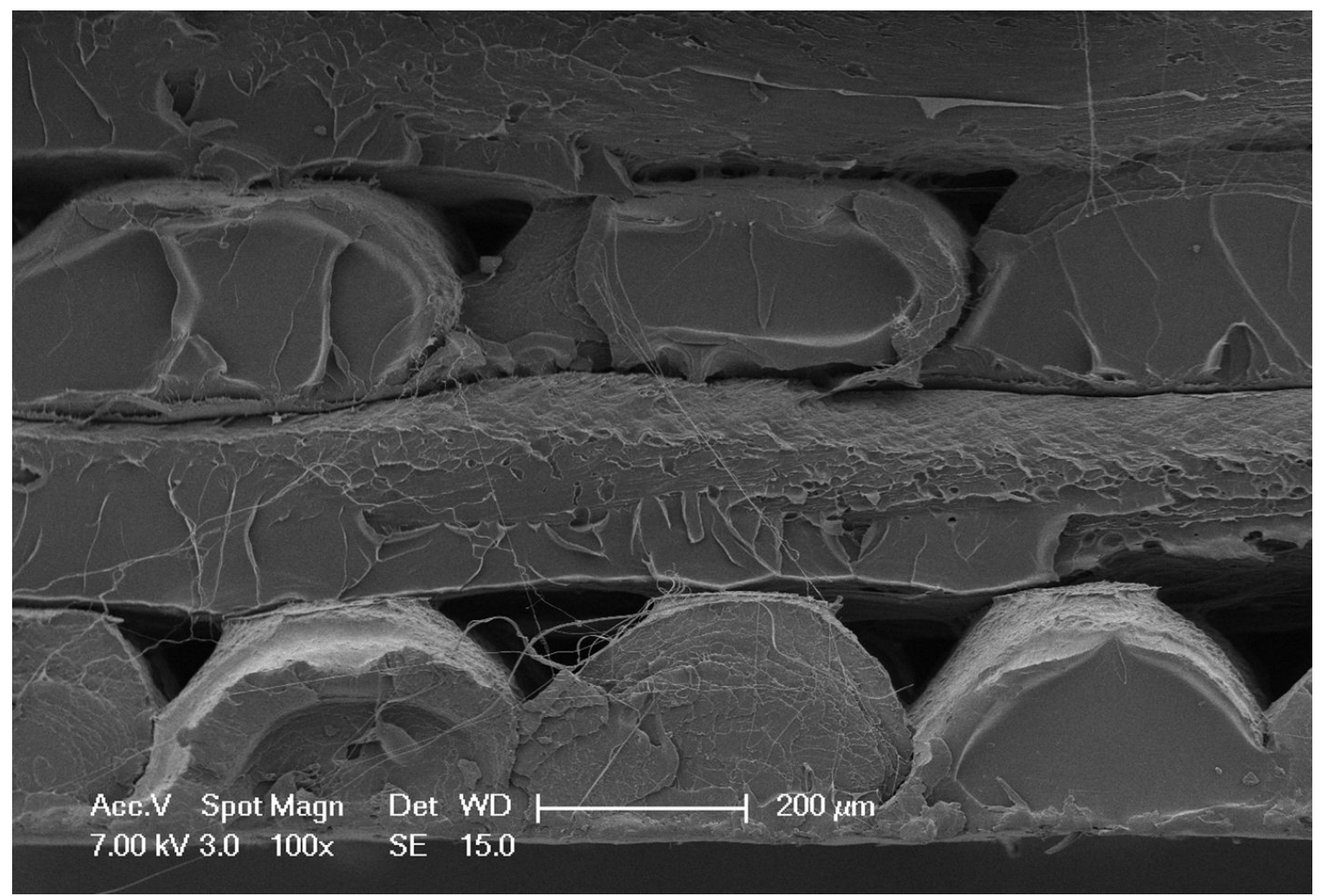

Figure 7: $\quad$ Scanning electron image of the white PLA sample printed at $190{ }^{\circ} \mathrm{C}$ showing the first four layers of the print with the bottom of the image corresponding to the bottom of the part when printing. 
Preprint: Wittbrodt, B., \& Pearce, J. M. (2015). The Effects of PLA Color on Material Properties of 3-D Printed Components. Additive Manufacturing. 8, 110-116 (2015). DOI: http://dx.doi.org/10.1016/j.addma.2015.09.006

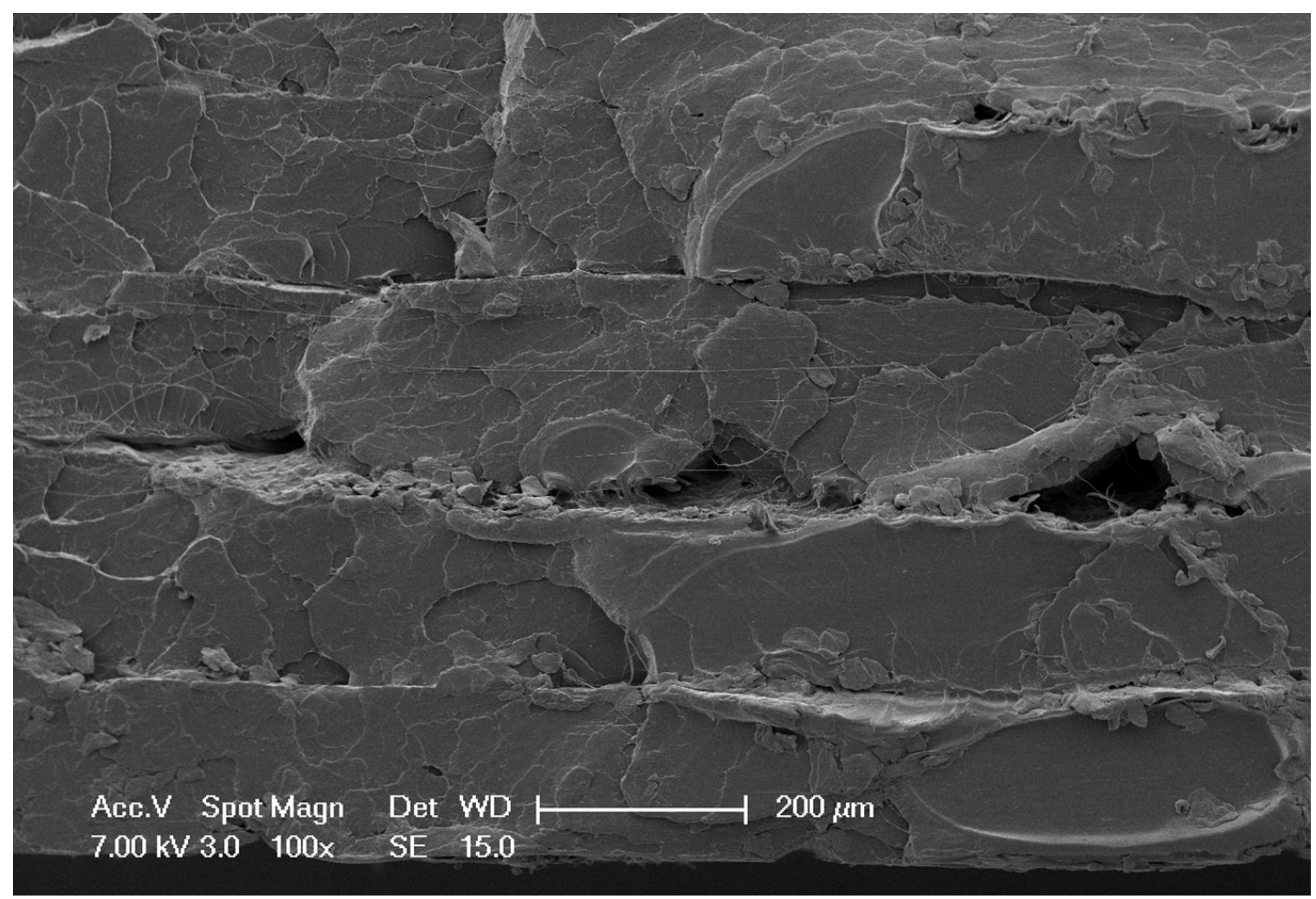

Figure 8: $\quad$ Scanning electron image of white PLA printed at $210^{\circ} \mathrm{C}$ oriented with the first printed layer on the bottom and including a total of 4 layers in the field of view.

The natural PLA sample was analyzed under the ESEM to attempt to provide more information regarding the material behavior and a high magnification image is shown in Figure 9. This sample showed a gap percentage of $10.6 \%$ when analyzed with imageJ. Figure 10 shows the gaps present in un-tested natural PLA showing that the gaps are present due to the nature of the printing process. 
Preprint: Wittbrodt, B., \& Pearce, J. M. (2015). The Effects of PLA Color on Material Properties of 3-D Printed Components. Additive Manufacturing. 8, 110-116 (2015). DOI: http://dx.doi.org/10.1016/j.addma.2015.09.006

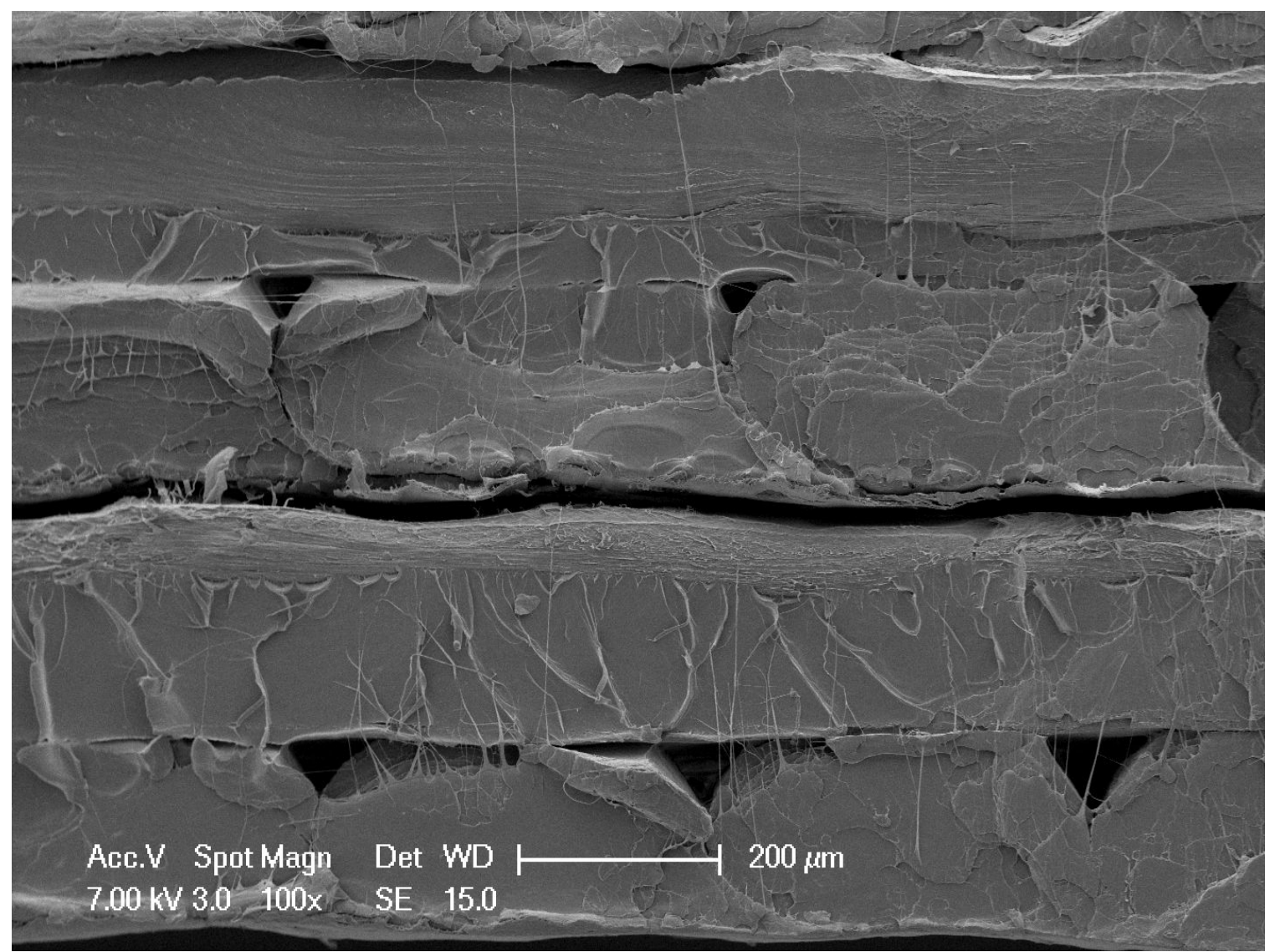

Figure 9: $\quad$ Natural PLA sample printed at $190^{\circ} \mathrm{C}$ imaged under the ESEM showing the bottom four layers oriented bottom layer at the bottom of the image. 
Preprint: Wittbrodt, B., \& Pearce, J. M. (2015). The Effects of PLA Color on Material Properties of 3-D Printed Components. Additive Manufacturing. 8, 110-116 (2015). DOI: http://dx.doi.org/10.1016/j.addma.2015.09.006

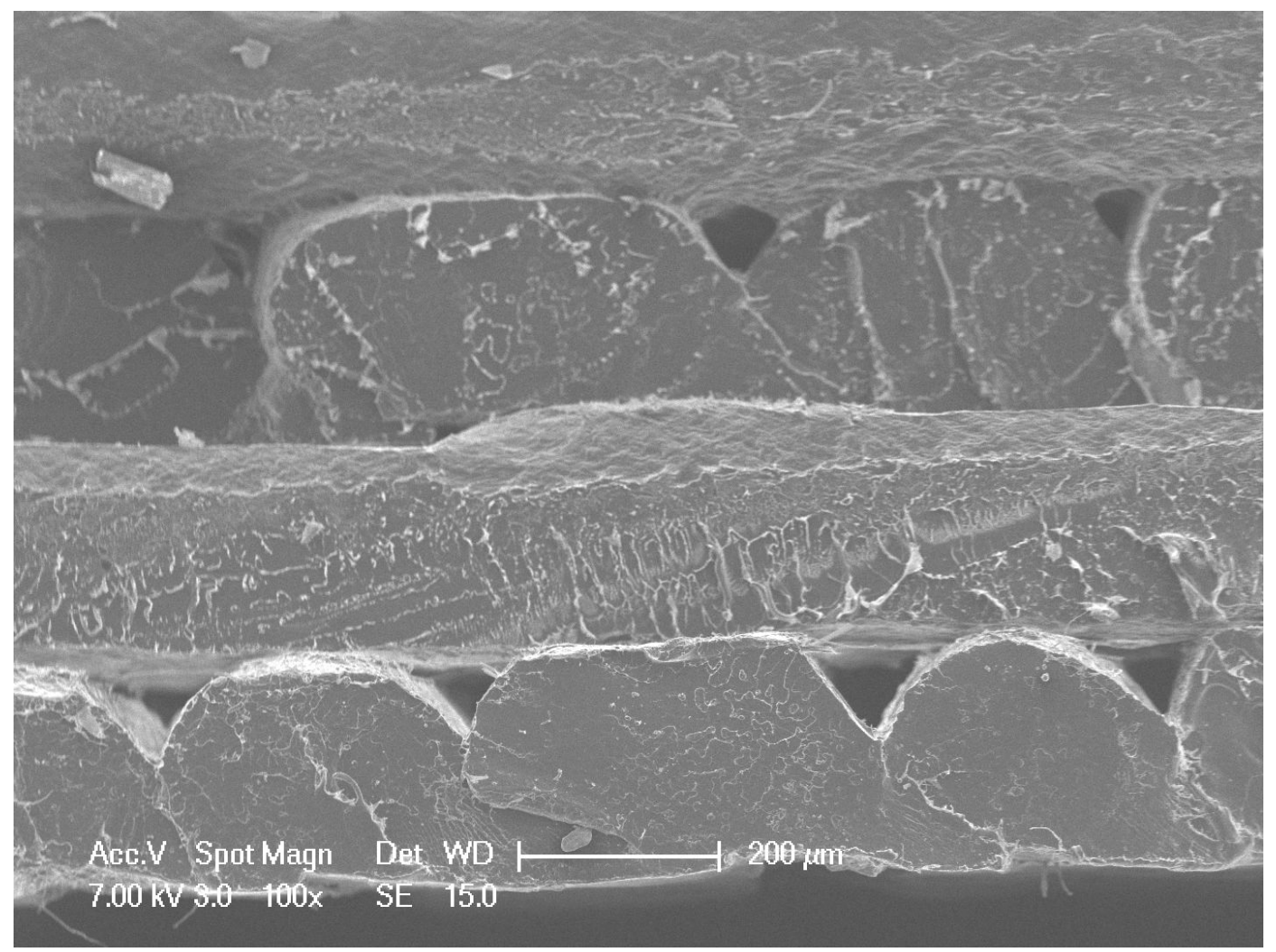

Figure 10: Raw sample of natural PLA (not tensile tested) showing the bottom 4 layers.

\section{Discussion:}

The data presented further verifies the claim that RepRap 3-D printers can produce parts of equal, or greater, tensile strength as prints from proprietary 3-D printers [27]. Furthermore the data was consistent with previously experienced behavior in tensile testing printed materials including PLA [36]. Additionally, all samples had a fairly constant Young's modulus of $2.78 \mathrm{GPa}(+/-0.35)$ which is in the acceptable range for PLA [37]. These 3-D printed parts may also be tailored for a given use by changing the color, or temperature the part is printed in. Each color presented, when printed at $190^{\circ} \mathrm{C}$, had a distinct tensile strength and percent crystallinity when analyzed with tensile testing and XRD. This shows that a conscious decision can be made for the choice of color that a part is printed in to achieve desired material properties. Also shown is the relative temperature dependence of a material's tensile strength and, again, percent crystallinity. While the tensile strength increases with temperature, the crystallinity increases from $190{ }^{\circ} \mathrm{C}$ to a maximum at $210^{\circ} \mathrm{C}$ and back down to a lower value at $215^{\circ} \mathrm{C}$ as seen in Table 2. Using this data it is possible to hypothesize that there can be a critical temperature of the percent crystallinity present in a given material. This is consistent with traditional polymer extrusion of PLA as it is well established that the crystallization of PLA can be initiated by annealing at temperatures higher than the glass transition temperature, but below the melting point to improve their thermal stability [37]. For example, in the case of injection molding annealing at $105^{\circ} \mathrm{C}$ for 90 min improved several properties including increased tensional and flexural elasticity, Izod impact strength, and heat resistance [38]. The effects of annealing on PLA are complex, as there are often two melting peaks observed based on melt-recrystallization model, in which small and imperfect crystals changed successively into more stable crystals through the melting and recrystallization [39]. In 
Preprint: Wittbrodt, B., \& Pearce, J. M. (2015). The Effects of PLA Color on Material Properties of 3-D Printed Components. Additive Manufacturing. 8, 110-116 (2015). DOI: http://dx.doi.org/10.1016/j.addma.2015.09.006

addition, it is well known that incorporating nucleating agents into plastics can modify the crystallization rate $[40,41]$, and the results here suggest that some of the coloring agents may be acting as crystallization rate modifiers.

The bed temperature was controlled to maintain $60^{\circ} \mathrm{C}$, during each print to ensure that any effect the heated bed may have had on the PLA is consistent throughout all samples.

The broad central peak between 16-17 in the XRD in Figures 2 and 3 and the increasing crystalline sharp peak is consistent with the annealing to create a larger crystalline volume fraction observed by Tabi et al., and verified with differential scanning calorimetry [42]. One possible explanation for the changing crystallinity is the different dyes used to color the PLA material. Since raw PLA has 0-1\% crystallinity [43], and the data presented here is consistent with that range, the addition of other dyes, strengtheners, or other agents must be the contributing factor for the different crystallinity percentages seen in the colored samples. Tensile strength differences can be explained by the behavior of the material itself. When the crystallinity is very low the strength is dependent on the material itself causing a high tensile strength. Crystallinity increases as printing temperature increases until it reaches a maximum value, $210^{\circ} \mathrm{C}$ in this case, and declines as temperatures become greater than the maximum. Tensile strength increased at every temperature except $200^{\circ} \mathrm{C}$, perhaps related to a preferential orientation of the crystalline grains perpendicular to the direction in which the samples were pulled at that temperature. Figures 5 and 6 show this potential relationship where $200^{\circ} \mathrm{C}$ has a minimum value of both strength and percent crystallinity.

When looking at the temperature dependence of the strength of the material the trend of tensile strength in respect to crystallinity is not followed. Once the material is printed at $215^{\circ} \mathrm{C}$ the tensile strength is higher but the percent crystallinity is lower than the critical crystallinity at $210^{\circ} \mathrm{C}$. Due to the layered nature of the 3-D printing process a higher printing temperature can give the different layers more time to bond together before cooling to the glass transition temperature.

Figures 2 and 3 show that there exist different crystalline peaks for samples that contain different percent crystallinities between colors. In Figure 5 there is a presence of higher degree peaks as the percent crystallinity increases showing that the lower degree peaks may not be essential in the strengthening process. Figure 3 illustrates the fact that the magnitude of the crystalline peaks will indeed increase when the percent crystallinity increases as expected.

Overall, the PLA samples tested had a lower tensile strength than the standard value for PLA (between 60 MPa and 70MPa [44]), as the process of 3-D printing allows different strands of plastic to be deposited in different orientations reducing the anisotropic nature of the strength if it were to be printed all in one direction. Also, while the sample was printed at a nominal 100\% fill percentage, Figure 7 shows that, at higher magnification, the PLA is not a completely solid material and has some gaps that could lower the ultimate tensile strength. As shown, when the PLA samples were examined under SEM, the average percentage of area represented by pores was $10.6 \%$ for natural and a tensile test of the raw filament showed a tensile strength of $63.64 \mathrm{MPa}$, or $11.4 \%$ stronger than the printed part. These results indicate that the colorant additives could play a role in the gaps size just as temperature does if as with lower temperatures some colorants restrict flow increasing the gap size. For example, the natural material (Figure 9) appears to have smaller "triangular-shaped" gaps than the white material (Figure 7). This, also explains the correlation between strength and strain shown in Figure 4. When the temperature was increased the layers adhered better together and nearer a solid material as presented in Figure 8. Figure 9 showing the natural PLA samples exhibits string-like artifacts over the fracture surface. These strings could potentially be amorphous chains of the base monomer extending under load and snapping once the stress surpassed the tensile strength causing fracture. 
Preprint: Wittbrodt, B., \& Pearce, J. M. (2015). The Effects of PLA Color on Material Properties of 3-D Printed Components. Additive Manufacturing. 8, 110-116 (2015). DOI: http://dx.doi.org/10.1016/j.addma.2015.09.006

This preliminary study had several limitations. The primary limitation is that all manufacturers of PLA filament are keeping their respective colorant additives proprietary trade secrets. This makes it challenging to explain the results as the additives are unknown. Future work is necessary to both characterize the properties of filaments before printing (e.g. with differential scanning calorimetry) and with chemical characterization to determine the additives. In addition, only a small subset of the colors were tested. A more detailed study is needed to test both the entire RBG, but also CMYK color series as many filament manufactures used combinations of the colored PLA to make more exotic colors. The complete range of colors could also be tested as a function of temperature similar to what was done here for white filament. This would allow for pinpointing optimal printing parameters as a function of color and colorant for commercially available filaments of which there are now several hundred varieties. In addition, it is already possible to change the color of a 3-D printed material by varying the temperature during printing For example, it is possible to print in the range from clear to white by varying print temperature by changing the microstructure. In addition, this technique has been used to print in wood grains in woodplastic composite filament such as LayWood [45]. Conversely as PLA filament is being sold for roughly ten times the cost of PLA pellets, it is likely that more 3-D printer users will purchase or construct some form of a recyclebot [19] and produce their own filament [11]. Then the study described here can be expanded to a much wider range of colors and different types of additives without the additional cost of characterizing unknown chemical additives. However, this will only be possible if the recyclebot community maintains open-source ethics related to filament recipes.

As RepRap printers become more sophisticated the ability to select colors and vary temperature for a specific component or part of a component will be possible and already these feature are supported in opensource slicing packages $[46,47]$ and some multihead printers (e.g. Lulzbot FlexyDually Tool Head ). Future work is needed to characterize all of the printing materials in this way to develop a database of material properties to be used in future generations of open-source slicing programs. In addition, the effect of printing speed on strength and percent crystallinity should be evaluated.

\section{Conclusions:}

With the rapid growth of the consumer FFF 3-D printing market and a large focus on providing useful, realworld applications of the technology comes an increasing demand to fully understand the material properties of the final 3-D printed components. Fused filament fabrication-style 3-D printers are able to produce parts with consistent material properties and it is also possible to estimate the properties expected using the presented data, which dependent on the color and extrusion temperature of the filament. According to the results of this study there appears to be a critical printing temperature for each color to optimize the crystallinity based on the results for white filament. Future work is needed to investigate the effects of printing temperature as a function of the other colors to create a matrix of properties allowing for a more complete material selection to be conducted.

\section{Acknowledgments}

The authors would like to thank Aleph Objects Inc. for their cooperation and assistance in providing the material and 3-D printer used in this study. The authors would also like to thank E. Laitila, G. Anzalone, and $\mathrm{O}$. Mills for technical assistance.

\section{References}

[1] E. Sells, Z. Smith, S. Bailard, A. Bowyer, and V. Olliver, RepRap: The Replicating Rapid Prototyper: Maximizing Customizability by Breeding the Means of Production, In Piller, F. T., and 
Preprint: Wittbrodt, B., \& Pearce, J. M. (2015). The Effects of PLA Color on Material Properties of 3-D Printed Components. Additive Manufacturing. 8, 110-116 (2015). DOI: http://dx.doi.org/10.1016/j.addma.2015.09.006

Tseng, M. M., Handbook of Research in Mass Customization and Personalization: Strategies and concepts (Vol. 1), World Scientific. (2010)

[2] R. Jones, P. Haufe, E. Sells, P. Iravani, V. Olliver, C. Palmer, and A. Bowyer, RepRap - the replicating rapid prototyper, Robotica. 29(01) (2011) 177-191.

[3] J. M. Pearce, C. M. Blair, K. J. Laciak, R. Andrews, A. Nosrat, and I. Zelenika-Zovko, 3-D Printing of Open Source Appropriate Technologies for Self-Directed Sustainable Development, J. Sustain. Dev. 3(4) (2010) 17.

[4] T. Wohlers, T. Caffrey, Wohlers Report 2014: 3D Printing and Additive Manufacturing State of the Industry Annual Worldwide Progress Report, Wohlers Associates. (2014)

[5] M. Molitch-Hou, Consumer 3D Printing in Growth Phase, 3D Printing Industry, [Online]. Available: http://3dprintingindustry.com/2014/08/14/consumer-3d-printing-serious-growth-phase-accordingphotizo-group/. [Accessed: 16-Nov-2014].

[6] C. Mota, The Rise of Personal Fabrication, in Proceedings of the 8th ACM Conference on Creativity and Cognition, New York, NY, USA, (2011) 279-288.

[7] B. T. Wittbrodt, A. G. Glover, J. Laureto, G. C. Anzalone, D. Oppliger, J. L. Irwin, and J. M. Pearce, Life-cycle economic analysis of distributed manufacturing with open-source 3-D printers, Mechatronics, 23(6) (2013) 713-726.

[8] M. Kreiger and J. M. Pearce, Environmental Impacts of Distributed Manufacturing from 3-D Printing of Polymer Components and Products, in Symposium D/G - Materials for Sustainable Development —Challenges and Opportunities. 1492 (2013) 85-90.

[9] J. Moilanen, V. Tere, Manufacturing in motion: first survey on 3D printing community. [Online] Available: http://surveys.peerproduction.net/2012/05/manufacturing-in-motion/. [Accessed: 22-Nov2014].

[10] J. G. Tanenbaum, A. M. Williams, A. Desjardins, and K. Tanenbaum, Democratizing Technology: Pleasure, Utility and Expressiveness in DIY and Maker Practice, in Proceedings of the SIGCHI Conference on Human Factors in Computing Systems, New York, NY, USA, (2013) 2603-2612.

[11] E. J. Hunt, C. Zhang, N. Anzalone, and J. M. Pearce, Polymer Recycling Codes for Distributed Manufacturing with 3-D printers, Resources, Conservation and Recycling 97 (2015) 24-30.

[12] D. L. King, A. Babasola, J. Rozario, and J. M. Pearce, Mobile Open-Source Solar-Powered 3-D Printers for Distributed Manufacturing in Off-Grid Communities, Challenges in Sustainability 2(1) (2014) 18-27.

[13] M. Groenendyk and R. Gallant, 3D printing and scanning at the Dalhousie University Libraries: a pilot project, Libr. Hi Tech. 31(1) (2013) 34-41.

[14] D. T. Pham and R. S. Gault, A comparison of rapid prototyping technologies, Int. J. Mach. Tools Manuf. 38(10-11) (1998) 1257-1287.

[15] X. Yan and P. Gu, A review of rapid prototyping technologies and systems, Comput.-Aided Des. 28(4) (1996) 307-318.

[16] A. R. T. Perez, D. A. Roberson, and R. B. Wicker, Fracture Surface Analysis of 3D-Printed Tensile Specimens of Novel ABS-Based Materials, J. Fail. Anal. Prev. 14(3) (2014) 343-353.

[17] B. G. Compton and J. A. Lewis, 3D-Printing of Lightweight Cellular Composites, Adv. Mater. 26(34) (2014) 5930-5935.

[18] S. Shaffer, K. Yang, J. Vargas, M. A. Di Prima, and W. Voit, On reducing anisotropy in 3D printed polymers via ionizing radiation, Polymer. 55(23) (2014) 5969-5979.

[19] C. Baechler, M. DeVuono, and J. M. Pearce, Distributed recycling of waste polymer into RepRap feedstock, Rapid Prototyp. J. 19(2) (2013) 118-125.

[20] J. M. Pearce, Building Research Equipment with Free, Open-Source Hardware, Science, 337(6100) (2012) 1303-1304.

[21] J. de Ciurana, L. Serenóa, and È. Vallès, Selecting Process Parameters in RepRap Additive Manufacturing System for PLA Scaffolds Manufacture, Procedia CIRP. 5 (2013) 152-157.

[22] J. M. Pearce, Open-Source Lab, 1st ed. Elsevier. 2014. 
Preprint: Wittbrodt, B., \& Pearce, J. M. (2015). The Effects of PLA Color on Material Properties of 3-D Printed Components. Additive Manufacturing. 8, 110-116 (2015). DOI: http://dx.doi.org/10.1016/j.addma.2015.09.006

[23] V. Vega, J. Clements, T. Lam, A. Abad, B. Fritz, N. Ula, and O. S. Es-Said, The Effect of Layer Orientation on the Mechanical Properties and Microstructure of a Polymer, J. Mater. Eng. Perform. 20(6) (2011) 978-988.

[24] L. Rosas, Characterization of Parametric Internal Structures for Components Built by Fused Deposition Modeling, University of Windsor. (2013)

[25] S. Ahn, M. Montero, D. Odell, S. Roundy, and P. K. Wright, Anisotropic material properties of fused deposition modeling ABS, Rapid Prototyp. J. 8(4) (2002) 248-257.

[26] Q. Sun, G.M. Rizvi, C.T. Bellehumeur, and P. Gu, Effect of processing conditions on the bonding quality of FDM polymer filaments, Rapid Prototyp. J. 14(2) (2008) 72-80.

[27] B. M. Tymrak, M. Kreiger, and J. M. Pearce, Mechanical properties of components fabricated with open-source 3-D printers under realistic environmental conditions, Mater. Des. 58 (2014) 242-246.

[28] D. G. Brady, The crystallinity of poly(phenylene sulfide) and its effect on polymer properties, J. Appl. Polym. Sci. 20(9) (1976) 2541-2551.

[29] D. M. Lincoln, R. A. Vaia, Z.-G. Wang, B. S. Hsiao, and R. Krishnamoorti, Temperature dependence of polymer crystalline morphology in nylon 6/montmorillonite nanocomposites, Polymer. 42(25) (2001) 09975-09985.

[30] D20 Committee, Test Method for Tensile Properties of Plastics, ASTM International. 2010.

[31] B. M. Tymrak, ASTM Tensile Test Specimen, Thingiverse. [Online]. Available: http://www.thingiverse.com/thing:13694. [Accessed: 22-Nov-2014].

[32] B. T. Wittbrodt X-Ray diffraction sample piece. Thingiverse. [Online]. Available: http://www.thingiverse.com/thing:559229. [Accessed: 22-Nov-2014].

[33] ACMAL, Scintag XDS-2000 Powder - ACMAL - Michigan Tech, [Online]. Available: http://mcff.mtu.edu/acmal/x-ray-facility/scintag-xds-2000-powder/. [Accessed: 16-Nov-2014].

[34] MOST, XRD (X-ray Diffraction) protocol: MOST. [Online]. Available: http://www.appropedia.org/XRD_(X-ray_Diffraction)_protocol:_MOST. [Accessed: 22-Nov-2014].

[35] ACMAL, Philips XL 40 ESEM. [Online]. Available: http://mcff.mtu.edu/acmal/electronmicroscopy/philips-xl-40-esem/. [Accessed: 22-Nov-2014].

[36] M. Domingos, F. Chiellini, A. Gloria, L. Ambrosio, P. Bartolo, and E. Chiellini, Effect of process parameters on the morphological and mechanical properties of 3D Bioextruded poly( $\varepsilon$-caprolactone) scaffolds, Rapid Prototyp. J., 18(1) (2012) 56-67.

[37] L. T. Lim, R. Auras, and M. Rubino. Processing technologies for poly (lactic acid). Progress in Polymer Science, 33(8) (2008) 820-852.

[38] G. Perego, G.D. Cella, C. Bastioli. Effect of molecular weight and crystallinity on poly(lactic acid) mechanical properties. Polymer, 59 (1996) 37-43.

[39] M. Yasuniwa, S. Tsubakihara, Y. Sugimoto, C. Nakafuku. Thermal analysis of the double-melting behavior of poly(l-lactic acid) J Polym Sci Part B: Polym Phys, 42 (2004), 25-32.

[40] R. Vasanthakumari, A.J. Pennings. Crystallization kinetics of poly(l-lactic acid). Polymer, 24 (1983), 175-178.

[41] J.J. Kolstad. Crystallization kinetics of poly(l-lactide-co-meso-lactide). J Appl Polym Sci, 62 (1996), 1079-1091.

[42] T. Tabi, I. E. Sajó, F. Szabo, A. S. Luyt, J. G.Kovács, Crystalline structure of annealed polylactic acid and its relation to processing. Express Polym Lett, 4(10) (2010), 659-668.

[43] MakeitFrom, Polylactic Acid (PLA). [Online]. Available: http://www.makeitfrom.com/materialproperties/Polylactic-Acid-PLA-Polylactide/. [Accessed: 20-Nov-2014].

[44] Proscpector, Polylactic Acid (PLA) Typical Properties. [Online]. Available: http://plastics.ulprospector.com/generics/34/c/t/polylactic-acid-pla-properties-processing. [Accessed: 21-Nov-2014].

[45] Laywoo-D3 [Online]. Available. http://reprap.org/wiki/Laywoo-D3 [Accessed: 20-May-2015].

[46] Ultimaker, Software Downlaods, Ultimaker. [Online]. Available: http://software.ultimaker.com. [Accessed: 22-Nov-2014]. 
Preprint: Wittbrodt, B., \& Pearce, J. M. (2015). The Effects of PLA Color on Material Properties of 3-D Printed Components. Additive Manufacturing. 8, 110-116 (2015). DOI: http://dx.doi.org/10.1016/j.addma.2015.09.006

[47] Slic3r, Slic3r. [Online]. Available: http://slic3r.org. [Accessed: 22-Nov-2014]. 